\section{Más allá de la pantalla: tres casos sobre la animación en los procesos académicos y de expresión artística de la Facultad de Artes de la Universidad de Antioquia (2000-2010)}

\section{Resumen}

Este artículo da cuenta de la investigación realizada sobre los procesos de experimentación y creación con animación que, entre los años 2000 y 2010, realizaron los estudiantes del Departamento de Artes Visuales de la Facultad de Artes de la Universidad de Antioquia. Esta pesquisa se enmarca en la investigación La Animación en Colombia 1990-2010, liderada por la Universidad de Bogotá Jorge Tadeo Lozano y en la cual el Grupo de Investigación Hipertrópico de la Universidad de Antioquia investigó la situación de la animación en Antioquia. Aunque la investigación nacional tiene por objetivo establecer un diagnóstico de la imagen animada desde la llegada de los medios digitales, el presente texto responde al análisis particular de los procesos creativos desarrollados con animación en la Facultad de Artes de la Universidad de Antioquia durante este periodo. La metodología de este análisis es cualitativa y hermenéutica, pues combina la reflexión sobre los procesos artísticos que integran la animación, considera la interacción entre estudiantes y profesores a la luz del uso de medios digitales y examina inductivamente creaciones artísticas con animación para plantear un posicionamiento estético y conceptual de las formas en las que se integró la imagen animada en procesos artísticos. Como resultados de la investigación se proponen tres categorías: convergencia de medios por necesidad expresiva, recursividad para trabajar la imagen en movimiento e interés en el medio como lenguaje de expresión. En ellas se evidencia cómo los estudiantes descubrieron, experimentaron y propusieron creaciones con o desde la animación. Se concluye de esta investigación que la animación en el Departamento de Artes Visuales de la Universidad de Antioquia durante el periodo estudiado se basa en la experimentación tecnológica, interdisciplinar y mediática que se integra a procesos de expansión formal en las artes.
Isabel Cristina Restrepo Doctora en Artes

Profesora titular, Universidad de Antioquia

Medellín, Colombia

cristina.restrepo@udea.edu.co

ำ orcid.org/0000-0002-8235-3525

Google Scholar

Alexandra Milena Tabares

García

Magíster en Historia del Arte

Profesora ocasional, Universidad de

Antioquia

Medellín, Colombia

alexandra.tabares@udea.edu.co

๑ orcid.org/0000-0002-1088-3164

Google Scholar

Carlos Mario Sánchez Giraldo

Magíster en Artes

Profesor cátedra, Universidad de

Antioquia

Medellín, Colombia

cmario.sanchez@udea.edu.co

ํ) orcid.org/0000-0002-0447-0785

Google Scholar

Sara Roldán Montoya

Magíster en Creación y Estudios

Audiovisuales

Universidad de Antioquia

Medellín, Colombia

sara.roldan@udea.edu.co

Orcid: 0000-0002-6424-4990

Google Scholar

Recibido: octubre 29 de 2018

Aprobado: marzo 02 de 2020

Palabras clave:

animación, convergencia de medios, artes visuales, experimentación artística, recursividad técnica. 


\section{Beyond the screen: three cases of animation in the academic and artistic expression processes in the School of Arts at Universidad de Antioquia (2000-2010)}

\begin{abstract}
This article gives an account of the research developed on the process of experimentation and creation with animation that students of the Department of Visual Arts of the Faculty of Arts at Universidad de Antioquia carried out between 2000 and 2010. This inquiry is part of the research La Animación en Colombia 1990-2010, led by Universidad Jorge Tadeo Lozano in Bogotá and in which the Hipertrópico Research Group of Universidad de Antioquia looked into and analyzed the status of animation in Antioquia. Although the national research aims to establish a diagnosis of the animated image since the arrival of digital media in Colombia, this text responds to the particular analysis of the creative processes developed with animation in the School of Arts of Universidad de Antioquia during this period. The methodology of this analysis is qualitative and hermeneutical, as it combines reflection on the artistic processes that make up animation, considers the interaction between students and professors in the light of the use of digital media, and inductively examines artistic creations with animation to propose an aesthetic and conceptual positioning on the ways in which the animated image was integrated into artistic processes. As a result, the research proposes three categories: convergence of means by expressive necessity, resourcefulness to work the moving image, and interest in the media of animation as a language of expression. In these categories, it is evident how the students discovered, experimented and proposed creations with or from animation. It is concluded from this research that animation in the Department of Visual Arts of Universidad de Antioquia during the period studied is based on technological, interdisciplinary and media experimentation that is integrated into processes of formal expansion in the arts.
\end{abstract}

Key words:

animation, media convergence, visual arts, artistic experimentation, technical recursion. 

procesos académicos y de expresión artística de la Facultad de Artes de la Universidad de Antioquia (2000-2010)

Introducción

.. the art of animation is not separable from its tools; it is "techno-art» or «techno-poetics».

Thomas LaMarre

El grupo de investigación Hipertrópico, convergencia entre arte y tecnología, adscrito a la Facultad de Artes de la Universidad de Antioquia, se vinculó en el año 2017 a la investigación La Animación en Colombia 1990-2010, coordinada por el profesor Ricardo Arce López de la Universidad de Bogotá Jorge Tadeo Lozano. Siendo parte del equipo coinvestigador, Hipertrópico indagó sobre el panorama de la animación en Antioquia durante las décadas precisadas. El rastreo, además de arrojar los insumos documentales que aportaron a la investigación liderada por el profesor Arce, evidenció la posibilidad de abordar las particularidades de la animación en el campo de las artes, es decir, las características de los procesos de creación donde la idea, la experimentación, la formalización y la divulgación de la pieza final responden a metodologías y estrategias aplicadas en los procesos creativos artísticos, las cuales distan significativamente de las cadenas de producción, financiación o proyección comercial.

De este hallazgo, se derivó el interés de Hipertrópico en focalizar el análisis en los procesos de formación llevados a cabo en los programas Artes Plásticas y Licenciatura en Educación Artes Plásticas de la Universidad de Antioquia. Lo anterior, teniendo en cuenta que al inicio del siglo XXI, en la oferta académica de estos pregrados, se propuso integrar las tecnologías digitales y los procesos de investigación sobre la creación artística en el marco de los talleres de integrado y de grado. Esto permitió la emergencia de experimentaciones con animación, en diálogo con medios como el dibujo, pintura, performance, instalación, video y multimedia. Surgieron así creaciones animadas que 
rompían el estándar tradicional de la pantalla de proyección y adquirían una dimensión espacial más allá de ella.

Se identificó que a partir del 2000, en los procesos de enseñanza en la Facultad de Artes se comienzan a integrar las tecnologías digitales, generando nuevas posibilidades para la experimentación y permitiendo que los lenguajes tradicionales de la creación plástica comenzaran a hibridarse con el video, la animación y la imagen digital. Al respecto, dice el docente Armando Montoya:

Fue por ahí en el año 2000 que (...) empezaron a plantearse aulas de tecnología por computador como procesos de aprendizaje para los estudiantes. Entonces, en las propuestas artísticas algunos estudiantes empezaron a ver esa dinámica, o esa estrategia, como una posibilidad expresiva. (Audio, 20 de febrero del 2018)

Esto permitió que los estudiantes experimentaran con medios audiovisuales en sus proyectos artísticos, especialmente la animación. El uso y apropiación que los artistas en formación hicieron de esta, particularmente en el marco de los Talleres de Integrado y de Grado, facilitó el desarrollo de proyectos en los que se expanden las posibilidades formales de los lenguajes artísticos, pues la animación fue puesta en diálogo con los demás medios de creación. En general, los estudiantes que trabajaron con animación hicieron un uso experimental del medio, planteando propuestas que iban más allá de los límites de la pantalla, permitiendo la emergencia de narraciones poéticas y expresiones propias que no se alineaban necesariamente con los cánones tradicionales de la estética audiovisual, ni con los modos de producción y las formas de proyección de la animación en ámbitos socioculturales como los del entretenimiento y lo comercial.

Para la escritura del presente artículo, se realizó un rastreo documental revisando las Memorias de grado de los egresados de artes plásticas, texto en el que consignan, a modo de reflexión escrita y visual, sus procesos de 
investigación-creación realizados en los talleres de integrado y de grado. De igual manera, se exploraron los catálogos de exposiciones locales, y, finalmente, los catálogos de las diferentes versiones del evento académico y expositivo Ecologías Digitales, liderado por el grupo de investigación Hipertrópico desde 2008, y que contó con la exhibición y divulgación de animaciones realizadas por estudiantes y egresados de los pregrados en cuestión. Una vez examinado este material, el cual se encuentra en el Centro de Documentación «Luis Carlos Medina Sarmiento» de la Facultad de Artes de la Universidad de Antioquia y en el archivo del grupo Hipertrópico, y finalizada la preselección de acuerdo con las décadas de observación (1990-2010), se identificaron y estudiaron un total de 13 memorias de grado, 9 catálogos de exposiciones y 4 catálogos del evento Ecologías Digitales.

Adicionalmente, se realizaron entrevistas semiestructuradas a varios de los artistas seleccionados, así como a profesores que acompañaron estos procesos de formación. La examinación de la información derivada en cada una de las etapas correspondientes a la recolección de datos, se articuló a consultas bibliográficas sobre estética, arte y animación, como requerimiento fundamental para la precisión de terminología, la orientación de las interpretaciones sobre los métodos y exploraciones creativas que dieron lugar a las animaciones, y la propuesta de las tres categorías para analizar los procesos de animación que dan cuenta de la forma como los artistas de la facultad trabajaron dichas creaciones durante sus experimentaciones artísticas, siendo estas categorías: Convergencia de medios por la necesidad expresiva, recursividad para trabajar la imagen en movimiento, e interés en el medio como lenguaje de expresión.

El análisis de la información recolectada permitió concluir que, en general, los desarrollos realizados con animación fueron más experimentales y rompieron los estándares de producción audiovisual, generando una estética híbrida de diferentes medios. Para dar cuenta de esto, se analizaron tres casos 
de artistas que trabajaron con la animación en su práctica como estudiantes en formación, los cuales se seleccionaron por destacarse en una de las categorías de análisis propuestas.

\section{Antecedentes de la integración de la animación en los procesos de formación y experimentación artística en la Facultad de Artes}

En el marco de los pregrados de Artes Plásticas y de Licenciatura en Educación Artes Plásticas, el encuentro con la imagen en movimiento sucede en la década de los años 90 a través de un taller de video impartido por el profesor e investigador Saúl Montoya Gutiérrez. Dicho taller abordaba la identificación y apropiación de herramientas análogas enfocadas a la producción audiovisual, estructurada principalmente bajo los parámetros de la narrativa clásica ${ }^{1}$. De igual manera, el taller procuraba motivar en los estudiantes la exploración del potencial creativo de la imagen en movimiento, recurriendo a ejercicios experimentales para el descubrimiento y aplicación de diferentes medios, técnicas y materiales.

A partir de juegos ópticos como el taumatropo ${ }^{2}$ y el estudio de la secuenciación fotográfica presente en los ejercicios de Eadweard Muybridge, el profesor ejemplificaba a los estudiantes en qué consiste la persistencia retiniana (Montoya, 2001, p. 31) y cuáles son los principios técnicos básicos de la descomposición del movimiento ${ }^{3}$, enfatizando en ellos a través de ejemplos

\footnotetext{
${ }^{1}$ La narrativa clásica cinematográfica, también llamada narrativa canónica (Bordwell, 1996) o narrativa aristotélica, hace referencia al modelo retórico propuesto por Aristóteles para la construcción y estructuración de obras dramatúrgicas. En este caso, una narración, ya sea teatral, audiovisual o cinematográfica, está compuesta por tres actos: inicio o planteamiento; medio, donde se desarrollan los conflictos que se plantearon inicialmente, y final, en el que se resuelven los conflictos.

${ }^{2}$ Taumatropo: «Dispositivo en el que se dibuja una imagen diferente en ambas caras de un disco, generalmente de cartón, que en el momento en que se hace girar a alta velocidad genera en el espectador la sensación de que las imágenes de cada lado se superponen» (Arce, Sánchez y Velázquez, 2013, p. 163).

3 «En el siglo xix, Eadweard Muybridge introdujo la técnica de la descomposición de secuencias de movimiento. Diseñó un sistema formado por tres baterías, de doce cámaras cada una, colocadas en ángulo recto una respecto a las otras. Todas enfocaron a un mismo sujeto. En cada instante, se disparaban sincrónicamente tres cámaras, una de cada batería, y así se obtenían exposiciones sucesivas con una diferencia entre sí de décimas de segundo» (Ratner, 2005, p. 111).
} 
provenientes del cine. A partir de estas demostraciones y de los abordajes teóricos y conceptuales, los estudiantes tenían la posibilidad de plantear sus propuestas audiovisuales realizando grabaciones con videocámaras de pequeño formato, capturas de clips de películas y ediciones analógicas. Si bien para la época mencionada la animación no era un asunto abordado en el taller de video, comprender que la sugerencia de movimiento puede aplicarse a las formas, tamaños, figuras, contornos y texturas evidenciaba para los estudiantes otros horizontes en la producción de imágenes secuenciales, como son los casos del dibujo cuadro a cuadro y el stop motion, técnicas recurrentes en los procesos particulares de acercamiento a la animación (S. Montoya, comunicación personal, 2 de marzo del 2018).

El taller de video permitió que algunos estudiantes identificaran la animación como un medio de creación artística a través del cual podían expresar sus ideas y reflexiones. Un ejemplo de esto es el caso del Maestro en Artes Plásticas Luis Ángel Castro Ruiz, quien para 1998 se encontraba inscrito como estudiante en el curso de video, cuando descubrió la imagen animada por medio de la realización de ejercicios en los que empleó el dibujo cuadro a cuadro, así como el papel recortado y la manipulación digital de imágenes escaneadas. Sus acercamientos experimentales derivaron en trabajos como Hellbound (1998), en el cual combinó el stop motion con la animación digital 2D y el cutout $^{4}$. Posteriormente, como auxiliar de programación en la Facultad de Ingeniería, Luis Castro aprendió sobre el uso de distintos programas empleados para el desarrollo de animaciones y aplicaciones multimediales, tales como Macromedia Flash ${ }^{5}$, con el que desarrolló su propuesta artística para el cierre de su formación profesional.

\footnotetext{
${ }^{4}$ Cut out: «También conocida como animación con recortes, es una técnica de animación planimétrica y progresiva realizada con recortes de papel u otro material plano, que generalmente son articulados para controlar el movimiento» (Arce, Sánchez y Velázquez, 2013, p. 160). ${ }_{5}$ «Macromedia Flash es una aplicación que permite crear páginas web de alto contenido interactivo, animaciones de todo tipo y juegos» (Orós, 2010, p. 1).
} 
Para 2007, como docente del Departamento de Artes Visuales, Luis Castro asume el primer Taller de Animación en 2D. Este taller exploraba la convergencia entre lo análogo y lo digital a través de las posibilidades técnicas ofrecidas por Macromedia Flash. De manera específica, la implementación de este programa como herramienta facilitó, de acuerdo con Castro, el redescubrimiento del dibujo cuadro a cuadro, el stop motion y la rotoscopia ${ }^{6}$, al ser estudiados como recursos y técnicas a partir de los cuales era posible generar reflexiones académicas y expresiones visuales desde la animación como lenguaje artístico (L. Castro, video, 22 de febrero del 2016).

En el marco de estos antecedentes académicos, asumir la animación como lenguaje artístico es una consecuencia del ejercicio exploratorio e investigativo sobre la descomposición del movimiento, realizado por los estudiantes. Posteriormente, la consideración de los resultados derivados de dicha exploración, aunada a las iniciativas de algunos profesores, devino en la configuración de talleres enfocados en la creación de animaciones artísticas.

\section{Espacios para la exploración artística con diferentes medios: talleres de integrado y de grado}

Desde 1993, los cursos Taller de Integrado y Taller de Grado se plantean como espacios en los que los estudiantes de los últimos semestres desarrollan, a través de un proceso de investigación-creación, propuestas artísticas en las que se evidencian sus intereses particulares en relación con el aprendizaje y la exploración de distintos medios de creación, como son la pintura, escultura, artes gráficas, video e imagen digital. Sobre los objetivos de los cursos, afirma Armando Montoya, docente de la Facultad de Artes y coordinador del Área de Integrado y Grado:

${ }^{6}$ Rotoscopia: «Técnica de animación planimétrica, en la que se filma a un actor para posteriormente calcar sus movimientos, dibujando cuadro a cuadro los fotogramas registrados» (Arce, Sánchez y Velázquez, 2013, p. 163). 
El área tiene unos objetivos fundamentales, que están basados en la posibilidad de que el estudiante entienda su proceso creativo como parte de una investigación formativa —no podemos perder eso de vista, estamos en un medio académico- que lo conduzcan a la producción en el campo de las artes visuales. Básicamente, son dos los componentes: la investigación formativa y los procesos creativos. Que el estudiante dimensione el arte como un proceso y comprenda que se formaliza sólo aquello que ha sido entendido y procesado. (Audio, 20 de febrero del 2018)

Por la forma como están planteados estos cursos, el estudiante tiene libertad para abordar su propio proceso. Después de una etapa juiciosa y consciente de investigación académica y experimentación formal, puede apropiarse de los medios que considere pertinentes para formalizar sus ideas y llegar a las configuraciones artísticas. Según Montoya:

En los Talleres de Integrado y de Grado es el estudiante quien trabaja de forma comprometida con el desarrollo de su obra. Los docentes cumplen el papel de orientadores, que guían el proceso de indagación particular de cada estudiante, sin imponer ejercicios o actividades específicas, como ocurre en los talleres de los primeros semestres de formación; pero sí sugiriendo al estudiante los posibles caminos a recorrer en su proceso de investigación-creación. (Audio, 20 de febrero del 2018)

Los estudiantes encuentran en los talleres la posibilidad de experimentar ampliamente con técnicas y lenguajes artísticos diversos, lo que da pie a la hibridación de medios y a propuestas formales sincréticas. En este contexto, la animación adquiere una gran relevancia para algunos de ellos, en el marco de los Talleres de Integrado y de Grado, pues la encuentran como un medio idóneo y potente para dar vida a sus ideas. Con respecto a los primeros trabajos de creación con animación presentados en los talleres, dice Montoya:

Empezaron a presentarse propuestas que (...) tenían un desarrollo a partir de los sistemas de animación por computador (...) [y] un vínculo con el espacio. La animación, en gran parte, estaba supeditada al dibujo manual que se procesaba por medios electrónicos. Algunos trabajos establecieron una relación espacial con el espectador cuando los estudiantes incluían dos pantallas, tres pantallas (...). Si bien eran situaciones muy experimentales, también hubo unos estudiantes que hicieron trabajos muy interesantes, de muy buena calidad y muy importantes para la época. La animación fue un medio que vinculado al espacio de emplazamiento de las pantallas, también vinculó al espectador, que en este caso era el mismo estudiantado que asistía a las evaluaciones de los talleres de integrado y de grado. Eso era fundamental. (Audio, 20 de febrero del 2018) 
Debido a que el acercamiento a la animación se dio como parte de un proceso de experimentación, en el que la intuición y la formación autodidacta jugaban un papel crucial para el desarrollo de la investigación-creación de los artistas en formación, muchos estudiantes llegaron a su encuentro a través de la exploración del dibujo, el video y la escultura, que al ser llevados a sus límites expresivos generaban inevitablemente la hibridación de lenguajes. Fue así como los estudiantes dieron origen a propuestas en las que la animación estaba en diálogo con otros medios, desbordando los límites de la pantalla bidimensional y de un solo canal, para hacer parte de obras en las que no solo la imagen audiovisual, sino también el espacio y el espectador, cobraban una gran relevancia. Esto permitía la emergencia de nuevas dinámicas de interacción entre el espectador y la animación, presente en las distintas propuestas.

\section{Más allá de la pantalla: experimentaciones artísticas con animación, en el marco de los procesos académicos del Departamento de Artes Visuales de la Universidad de Antioquia}

El siglo xxi trajo consigo la oportunidad de que en muchos hogares de Colombia fuera posible la adquisición de computadores. Este acceso a las tecnologías digitales, aunado al advenimiento de internet, vinculó la tecnología digital a la cotidianidad del ciudadano, y a su vida laboral y de esparcimiento; y también favoreció el acercamiento a la animación en los ámbitos personales y académicos, asunto que en otros lugares del mundo ocurría desde 1990. Christiane Paul (2003), historiadora del arte digital, dice lo siguiente al respecto:

La década de 1990 fue testigo de un desarrollo tecnológico de velocidad sin precedentes para el medio digital: la llamada «revolución digital». Aunque los fundamentos de muchas tecnologías digitales se habían establecido sesenta años antes, estas tecnologías se volvieron aparentemente omnipresentes durante la última década del siglo xx. El hardware y el software se volvieron más refinados y asequibles, y el advenimiento de la World Wide Web a mediados de la década de 1990 agregó una capa de «conectividad global». (p. 7) 
A través de sus procesos de investigación-creación, y en el contexto académico del Departamento Artes Visuales, varios estudiantes llegaron de forma experimental a la formalización de propuestas en las que la animación era uno de sus componentes o el medio de expresión principal, aunque no fuese mencionada explícitamente en las fichas técnicas. Algunos de ellos fueron: Verónica María Moreno, Ingridmar García, Carlos Mario Sánchez, Lina Marcela Castaño, Sebastián Tabares, Carlos Londoño, Alexandra Milena Tabares, Juan Pablo Rogers, Lina Marcela Castañeda, Julián Bedoya, Samanta Duque, Diana Sánchez, María Juliana Ochoa y Yuliana Quiceno. Ellos utilizan la animación de múltiples formas: partiendo del dibujo; con programas informáticos como Adobe Photoshop, Macromedia Flash y Movie Maker; integrando las animaciones a propuestas escultóricas, instalaciones o puestas en escena; o pensando directamente en la animación, para proyectarla en pantallas de televisión. En los procesos creativos y experimentales de los estudiantes, la integración tecnológica se vio fortalecida con la creación de los talleres complementarios en Imagen Digital, en los primeros años de la década del 2000. En general, puede decirse que las exploraciones de los estudiantes dan cuenta de formas de inserción de la animación en el arte contemporáneo, lo cual es expresado por Jaime Munárriz (2012) en los siguientes términos:

La animación empieza a ocupar un lugar importante entre los medios y soportes utilizados en la creación artística contemporánea. Integrándose en piezas, instalaciones, junto a dibujos y otros elementos, las formas toman movimiento y rompen el estatismo habitual en salas de exposiciones y galerías. Las obras contemporáneas se empapan de la cultura audiovisual que nos rodea, absorbiendo la sustancia de sus imágenes siempre cambiantes. (p. 1)

Adicionalmente a los aspectos pedagógicos y de integración tecnológica en los procesos de formación y experimentación con animación de la Facultad de Artes, encontramos relaciones que nos permiten proponer tres categorías de hibridación de medios, por las cuales los artistas en formación llegaron a trabajar con animación, estas son: convergencia de medios por la necesidad 
expresiva, recursividad para trabajar la imagen en movimiento e interés en el medio como lenguaje de expresión.

\section{Convergencia de medios por la necesidad expresiva}

En muchos casos, la utilización de la animación por parte de los artistas en formación se daba como resultado de una experimentación con diversos medios de expresión artística, hasta encontrar el lenguaje más apropiado a los intereses particulares de cada proyecto. Este lenguaje se genera como resultado de una convergencia mediática, que podemos analizar desde las referencias artística y tecnológica. Desde la artística, nos referimos a la ruptura de las fronteras de los medios artísticos dada en el arte desde mediados del siglo xx, permitiendo la articulación de nuevos medios — video, animación, arte digital_ con medios análogos tradicionales — pintura, escultura, instalación-. Desde la perspectiva tecnológica, podemos vincular la convergencia de medios en las exploraciones artísticas de los estudiantes con el concepto de convergencia mediática propuesto por Henry Jenkins, cuando hace alusión a la "colisión entre los viejos y los nuevos medios", y señala que "el emergente paradigma de la convergencia asume que los viejos y nuevos medios interaccionarán de formas cada vez más complejas" (Jenkins, 2006, p. 17), y que "convergencia es una palabra que logra describir los cambios tecnológicos, industriales, culturales y sociales en función de quienes hablen y de aquello a lo que crean estar refiriéndose" (p. 14).

En general, al analizar las propuestas artísticas que llegaban a una convergencia de medios, e integraban la animación por una necesidad expresiva en los talleres de integrado y de grado, encontramos que parecen responder a una suerte de experimentación con nuevos medios, bajo la lógica expresiva y creativa sugerida por José Alejandro Restrepo cuando señala lo siguiente: 
Una vez más, deberían pensarse los nuevos medios en su capacidad poética y su fuerza vital. Podríamos, a través de estas metamorfosis producidas por la tecnología, entrar al lugar privilegiado de la creación misma y desde ese escenario misterioso acercarnos a la producción de las obras. (Restrepo, 2005, p. 226)

En esta categoría nos parece importante analizar la obra de la artista Yuliana Quiceno, quien adopta el recurso de la animación en algunas de sus experimentaciones artísticas, proponiendo dinámicas objetuales y espaciales en las que la animación aparece no solo en formatos expandidos sino también invitando al espectador a acceder a la imagen de forma activa. Conceptualmente, sus propuestas constituyen experiencias inmersivas y metafóricas que hablan de la casa, el tiempo y la memoria. La artista busca "generar atmósferas que puedan invadir al espectador de un sentimiento evocador" (Quiceno y Grajales, 2012, p. 33), centrándose en formalizaciones poéticas alejadas de la literalidad conceptual o autobiográfica de sus motivaciones y a partir de la convergencia de medios como el dibujo, la instalación, la animación y el performance.
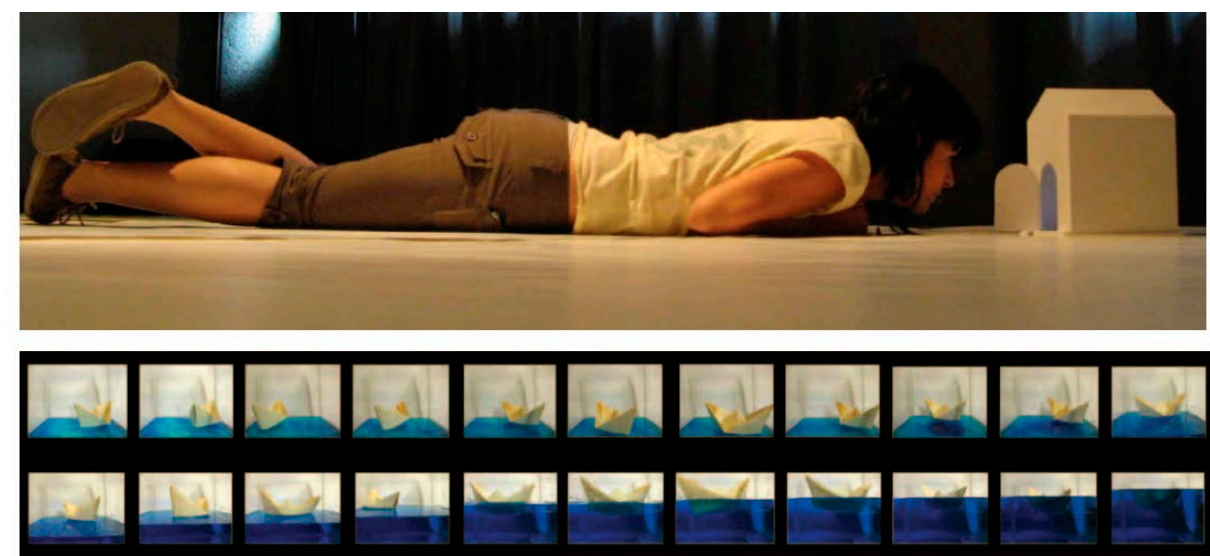

Figura 1. Sin título. Videoinstalación. Arriba, registro fotográfico de una espectadora interactuando con la videoinstalación abajo, fotogramas de la animación reproducida en la pantalla ubicada dentro de la casa de papel en pequeño formato. Fuente: Quiceno (2007) 
En 2008, Quiceno realiza la obra La ventana, en la que convergen medios como la animación, la instalación y el dibujo. Conceptualmente, para esta obra la artista retoma una frase del primer libro sobre Peter Pan titulado The little white bird, "el cual decía que los niños antes de nacer eran pájaros que volaban desde los jardines de Kensington hasta el vientre de las madres" (Quiceno y Grajales, 2012, p. 41). Formalmente, la artista propone un diálogo de medios, con tres planos de realidad: una jaula blanca para pájaros, que flota en el espacio; sobre la pared se encuentra el dibujo de una ventana, "que actúa como una apertura entre lo real y lo irreal" (p. 41), y, enmarcado sobre el área de la ventana, se proyecta la animación cuadro a cuadro de un pájaro cuyo vuelo está contenido en los límites de la hoja de papel. De esta forma, Quiceno representa la memoria a partir de una convergencia de medios que cuestionan los límites entre lo real y lo irreal, a partir de la imagen de un pájaro que ya no está encerrado en una jaula, sino en una hoja de papel —como soporte de su representación animada-.

Como trabajo final de su etapa de talleres, Yuliana lleva sus experimentaciones sobre la animación al ámbito del performance, en la obra del 2008 titulada Sin título. Para esta obra, la artista proyecta sobre una pared una animación del vuelo de un ave realizada con dibujos. El espacio del vuelo deja de tener un carácter atmosférico realista, para generar un espacio virtual de representación donde la trayectoria del vuelo y el reposo se dibujan sobre los renglones de la imagen de una hoja de papel. Mientras la animación es proyectada, la artista intenta dibujar el ave en distintas posiciones. El carácter volátil del pájaro impone un ritmo a la acción de la artista en el espacio, así como a los trazos resultantes en la pared. 

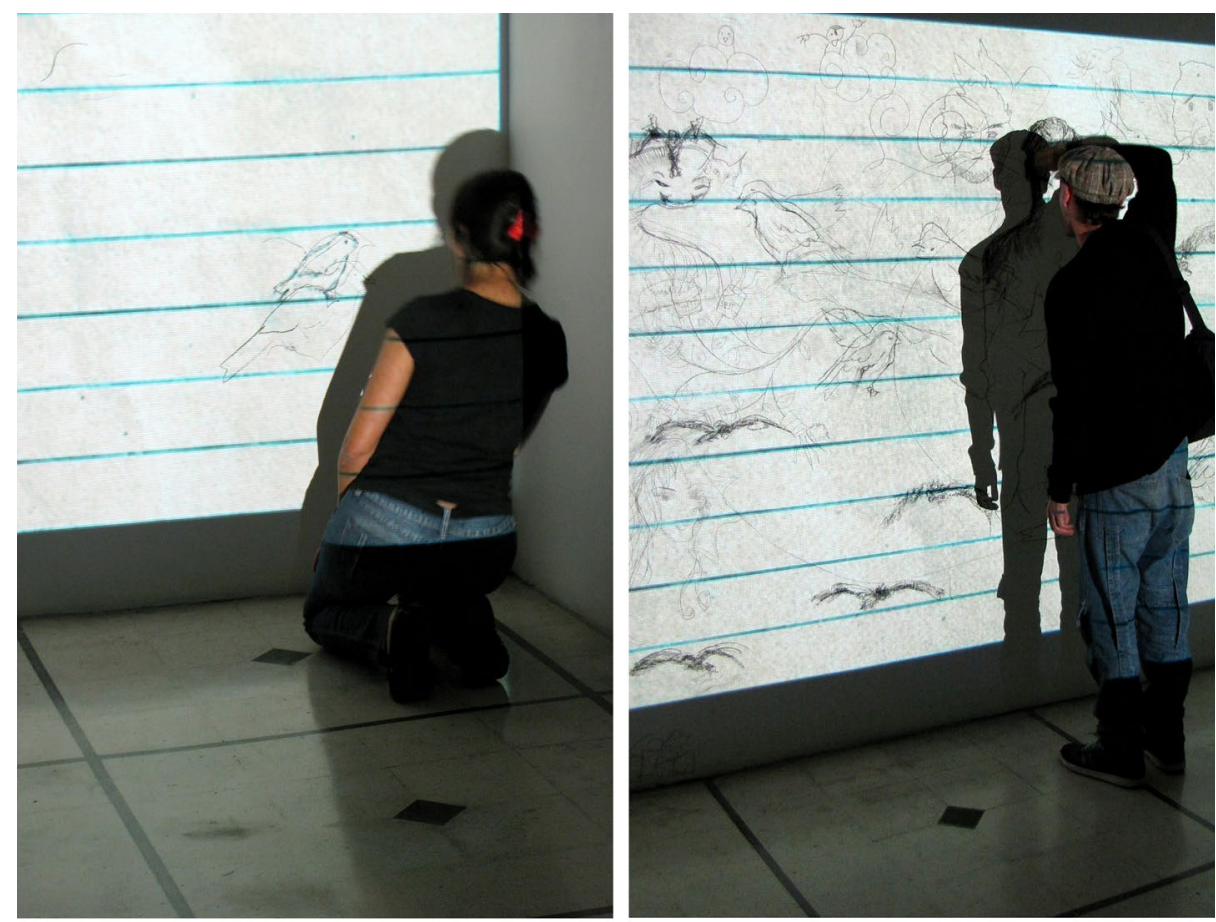

Figura 2. Vuelo de pájaro o grafito. Performance. Registro fotográfico de dos espectadores interactuando con el grafito y la proyección al finalizar la acción.

Más tarde, en 2010, la artista realiza una nueva versión de esta última propuesta, en el marco del evento Ecologías Digitales. En esa oportunidad la artista brinda la posibilidad de que al finalizar el performance el público intervenga la obra con sus dibujos. La invitación a la acción de los espectadores es silenciosa, sin instrucciones. Tan solo bastó disponer diferentes grafitos en el espacio al finalizar el performance, para que los asistentes se convirtieran en 
agentes activos, con diferentes niveles de creación. Una posibilidad creativa se daba en quienes, a medida que dibujaban, intentaban captar el ave en sus distintas posiciones; otra posibilidad estaba en quienes realizaban dibujos más libres, expandiendo la acción del dibujo calcado hasta una expresión gráfica particular.

En general, el interés principal de la artista, en sus diferentes exploraciones con animación, es darle vida a un objeto para proponer un diálogo poético entre realidad y ficción, a partir de la convergencia de medios como el dibujo, la instalación, el performance y la animación. Como estrategia formal para darle vida a los objetos, Yuliana parte del dibujo como medio base para la construcción de fotogramas que, por la fuerza del trazo manual, adquieren un nivel de expresividad liviano, emotivo y sensible, posible tan solo por su pulsión poética. La diversidad del formato y tamaño de las pantallas que utiliza, su acción en algunos performances y la invitación a la acción que hace a los espectadores en algunas de sus propuestas, dan cuenta de experimentaciones con animación que van más allá de los límites de la pantalla convencional de proyección.

\section{Recursividad para trabajar la imagen en movimiento}

En esta investigación se ha identificado que, en el contexto académico aquí expuesto sobre los años 2000-2010, la carencia de cámaras de video y de software de edición es la constante para un alto porcentaje de los estudiantes interesados en la producción audiovisual. Sin embargo, algunos de ellos no asumen dicha carencia como una limitación, más bien la conciben como una invitación para encontrar otro tipo de recursos plásticos y visuales a través de los cuales puedan formalizar aquellas propuestas donde la imagen en movimiento es consecuencia fáctica del ejercicio conceptual. En otras palabras, a la animación los estudiantes Ilegan también por la naturaleza del 
proceso de investigación para la creación, así como por la disposición creativa que el artista en formación debe asumir respecto al trasegar tecnológico.

Este panorama dialoga con el planteamiento señalado por el profesor Ricardo Arce López, investigador principal del proyecto La animación en Colombia 1990-2010, cuando afirma: "Desde el momento en que existe la tecnología necesaria para grabar o registrar la imagen en movimiento, o las fases de este de manera secuencial, existe así mismo la posibilidad de realizar animación" (Arce, Sánchez y Velásquez, 2013, p. 40). En tal sentido, puede entenderse que la recursividad tecnológica es inherente a la producción de animaciones y, por tanto, no se limita a las necesidades estéticas, expresivas, poéticas o narrativas de la imagen en movimiento. Dicho de otra manera: "En la técnica hay opciones. $\mathrm{Y}$ hay que saberlas seleccionar de acuerdo con nuestras necesidades. $\mathrm{Y}$ hay que saberlas poner a disposición del hombre y no para sumisión del hombre" (Alonso y Mantilla, 2001, p. 167).

La recursividad se convierte en fundamento creativo para realizar propuestas artísticas donde la pregunta por la imagen en movimiento, como obra, es respondida a través de la animación. En esta ruta, el artista Julián Bedoya Santamaría, Licenciado en Artes Plásticas de la Universidad de Antioquia, y quien durante su época de estudiante exploró la imagen animada a partir de su interés por el video y la falta del recurso técnico básico, expresa lo siguiente:

(...) yo no tenía cámara de video pero sí tenía una cámara digital pequeña que me permitía hacer fotos. Entonces, con toda la intención de hacer video, pero sin la herramienta, empecé a hacer stop motion. (J. Bedoya, comunicación en audio, 14 de septiembre del 2017)

El artista fundamenta su producción en la experimentación audiovisual y la narrativa no convencional, así como en la exploración técnica y la apropiación del lenguaje de diversos medios tecnológicos. Sus obras, de acuerdo con Bedoya, pretenden activar en el espectador reflexiones que inviten a pensar en el error como algo inherente a la existencia, y en la importancia de acercarse a 
las posibilidades de recontextualización y descontextualización del objeto, así como a lo velado y lo develado a través de una imagen (J. Bedoya, comunicación en audio, 14 de septiembre del 2017).

Bedoya encuentra en la animación su línea formal para configurar la obra. A partir de la apropiación de medios análogos y digitales, explora técnicas de secuenciación clásica de imágenes para simular movimiento, las cuales dispone en diálogo con técnicas digitales que le permiten intervenir las imágenes, en una suerte de exploración lúdica con el lenguaje audiovisual. Como ejemplo, se referencia a continuación la serie de cuatro piezas animadas, denominada El barquito (2008).

En "Un barquito (estudios de stop motion)", el artista le propone al espectador un encuentro con la imagen, partiendo de la identificación del flipbook ${ }^{8}$ como objeto, como soporte del dibujo y como técnica de animación. Por su parte, en "Un barquito, 2 (estudios de stop motion)", la propuesta pasa al stop motion intervenido digitalmente, como hibridación técnica para evidenciar la construcción y deconstrucción paso a paso de un barco de papel dispuesto sobre un fondo blanco. Aquí el artista prioriza la identificación del material, el proceso de doblez para el armado y el reconocimiento del objeto final.

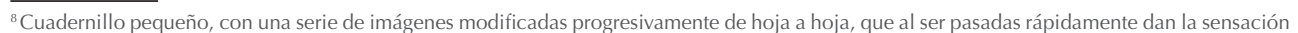
de movimiento. 

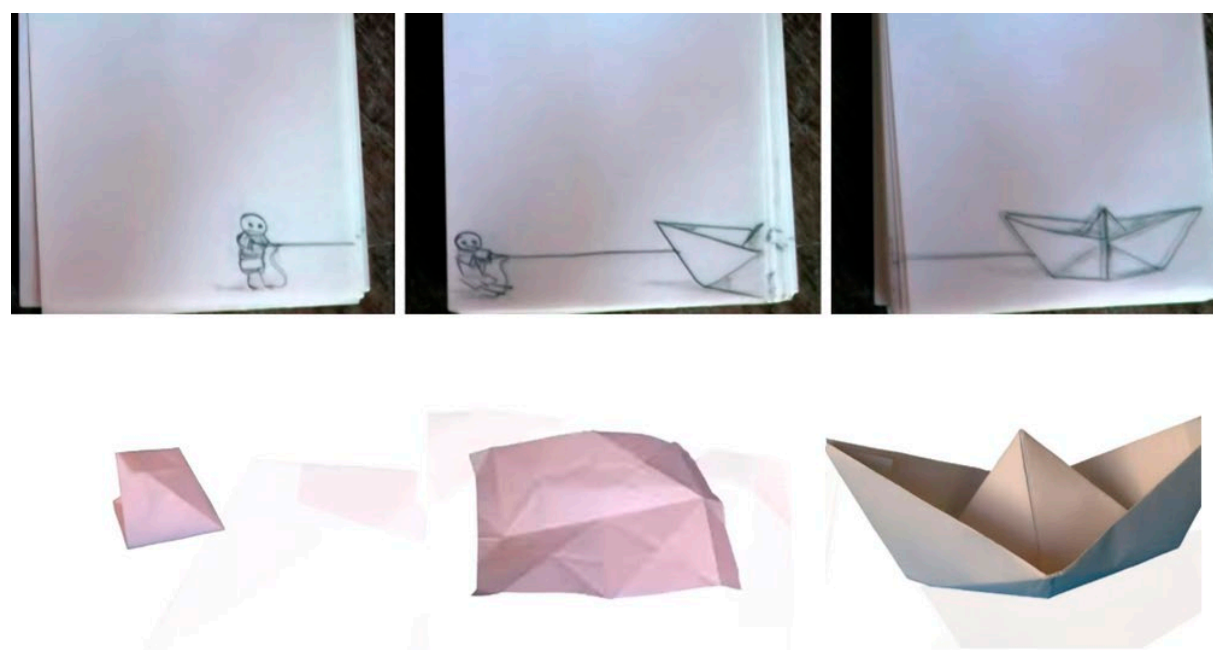

Figura 3. Un barquito (estudios de stop motion) y Un barquito, 2 (estudios de stop motion). Stop motion. Arriba, fotogramas de la pieza Un barquito (estudios de stop motion); abajo, fotogramas de la pieza Un barquito, 2 (estudios de stop motion).

Fuente: Bedoya (2008)

Para "Un barquito, 3 (estudios de animación y stop motion)", Bedoya continúa con técnicas digitales de animación y de ilustración para manipular los registros fotográficos de dibujos y secuencias de armado del barco, tratándose de un diálogo visual entre la fotografía y el dibujo, para la configuración de escenarios naturales en los que el objeto barco se desplaza y establece relaciones con los demás elementos visuales. Finalmente, "Un barquito, 4 (estudios de stop motion)" articula una narrativa en la que se capitalizan elementos visuales que han configurado piezas anteriores, destacándose el registro fotográfico de la ilustración análoga sobre pared, sin evidentes intervenciones digitales en posproducción, así como la presencia del artista como ilustrador. 


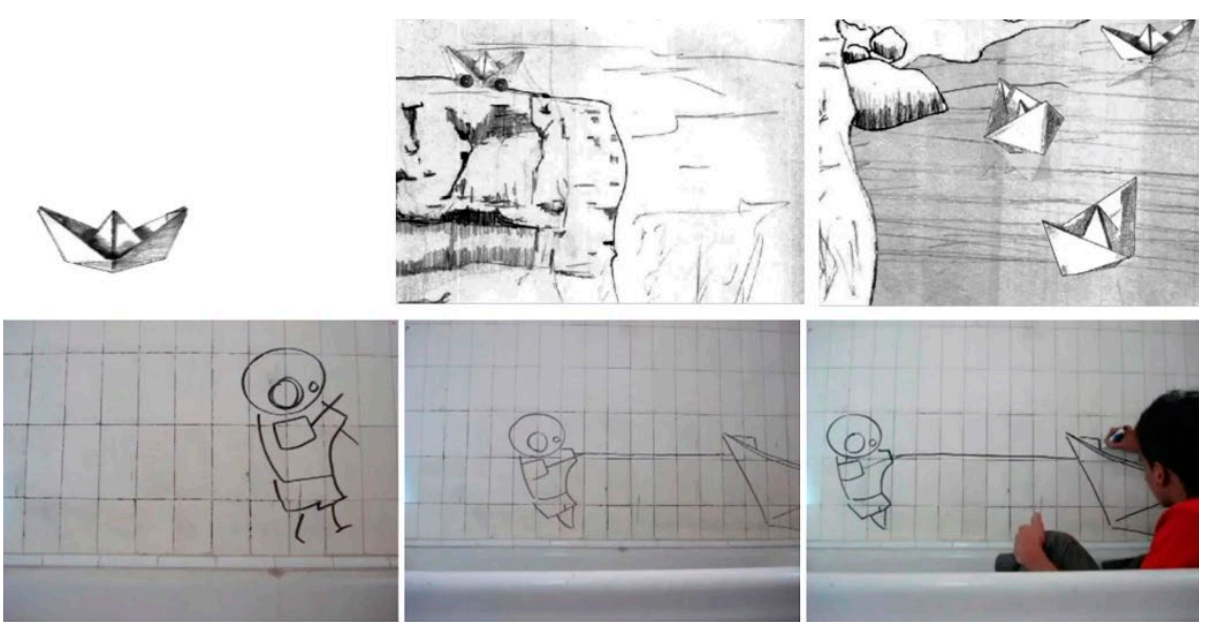

Figura 4. Un barquito, 3 (estudios de animación y stop motion) y Un barquito, 4 (estudios de stop motion). Animación, stop motion. Arriba, fotogramas de la pieza Un barquito, 3 (estudios de animación y stop motion); abajo, fotogramas de la pieza Un barquito, 4 (estudios de stop motion).

Fuente: Bedoya (2008).

Esta serie de animaciones del artista Julián Bedoya dan cuenta de su proceso experimental, a través del cual le es posible comprender y dominar el lenguaje del medio; así como de la identificación y aprovechamiento de diversos recursos técnicos y tecnológicos, con los cuales formaliza sus producciones. Estos recursos, desde el punto de vista conceptual, se articulan con la intención que tiene de activar en el espectador reflexiones sobre el error, la recontextualización, la deconstrucción, lo velado y lo develado en la imagen y a través de ella.

\section{Interés en el medio como lenguaje de expresión}

Finalmente, como categoría de análisis de las propuestas experimentales desarrolladas por los estudiantes, está la del interés en la animación como 
un medio de expresión en sí mismo, y, en particular, en sus potencialidades para crear diversas formas narrativas y comunicacionales. De esta forma, hay una inclinación por la animación como un medio que se abre a posibilidades de crear relatos con cierto sentido fantástico, en los que las imágenes no solo cobran vida a partir del movimiento, sino que también crean universos imaginarios a través de los cuales los estudiantes pueden poner en escena sus inquietudes particulares. Según el animador, director y productor estonio Ülo Pikkov: "Desde las etapas tempranas de su existencia, la humanidad se ha dirigido hacia la fantasía, hacia la creación de universos imaginarios, hacia la dotación de vida a objetos inertes" (Pikkov, 2010, p. 36)

En la pulsión humana por crear historias, algunos de los estudiantes de la Facultad de Artes encuentran una justificación que les permite reflexionar sobre la realidad como una construcción ficcional en la que también tiene cabida lo fantástico. La animación se convierte, entonces, en un medio idóneo con el que se pueden crear imágenes que evocan la ensoñación y la ficción, sin la necesidad de usar grandes recursos tecnológicos; los cuales serían necesarios para hacer una propuesta de esta misma naturaleza, con el empleo exclusivo de los medios videográficos o cinematográficos. Esto representa una gran ventaja, pues, además de los bajos costos, la animación ofrece múltiples posibilidades estéticas y de estilo en su amplia gama de técnicas. Respecto al interés por trabajar la animación como medio para construir historias fantásticas, encontramos el trabajo de la artista Samanta Duque, egresada del Programa de Artes Plásticas, quien durante su proceso en los talleres de integrado y de grado exploró varias posibilidades narrativas con animación, a partir de instalaciones realizadas con el uso de varias pantallas. Al respecto de su interés por la narración fantástica, la artista expresa: 
Quiero que todos vean lo imposible o lo increíble a través de lo visual, trayendo los sueños a la realidad, que exista una confusión entre ellos y que no podamos distinguir uno del otro (...). Estos videos llevan la realidad que acostumbramos a otro nivel. (Duque, 2011, p. 15)

Duque eligió la animación como medio para formalizar su trabajo artístico y creativo, pues encontró en ella una coherencia directa entre el mensaje que quería expresar y las posibilidades plásticas que le brindaba. Adicionalmente, al hibridar la animación con la instalación les otorgó a sus obras una dimensión espacial que creaba nuevas dinámicas con los espectadores. Sus animaciones son realizadas con las técnicas de pixilación ${ }^{10}$ y stop motion, a través de las cuales se crean secuencias al cambiar, fotograma a fotograma, las poses de actores humanos y objetos para construir el sentido fantástico de sus narrativas. En ellas, sus personajes, inmersos en el tedio de la cotidianidad, poco a poco se ven envueltos en situaciones extrañas, en donde la realidad se confunde con los sueños y se transforma en un absurdo, permitiendo la aparición de narrativas en las que se difuminan las fronteras entre lo real y lo ficticio. Entre las obras realizadas con esta estrategia narrativa, encontramos: Como en un sueño (2009), Sin salida (2009), Locura en el encierro (2009) y Comienza un buen día (2010).
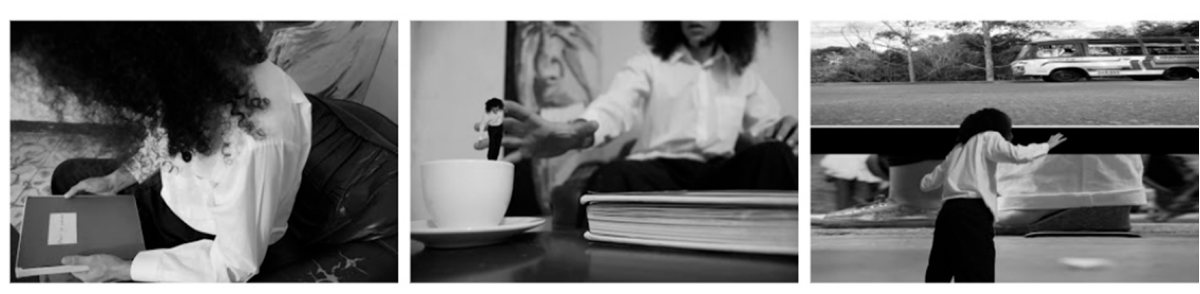

Figura 5. Sin salida. Animación stop motion y pixilación. Fotogramas. Fuente: Duque (2009).

\footnotetext{
${ }^{10}$ Pixilación: "Técnica de animación volumétrica y progresiva en la que se construyen, cuadro por cuadro, secuencias transformando las poses de un actor, fragmentando el movimiento real y permitiendo que interactúen muñecos, objetos y personas en una producción animada" (Arce, Sánchez y Velázquez, 2013, p. 163).
} 
Ella opta conscientemente por la animación como medio principal para el desarrollo de su propuesta, empleando la pixilación y el stop motion como técnicas principales de sus animaciones, pues al estar basadas en imágenes fotográficas parecieran ser más cercanas al sentido de realidad de aquello que representan, como ocurre en la estética cinematográfica, y contrario a lo que sucede con otros medios utilizados comúnmente en la animación, como son el dibujo y la pintura. Precisamente, esta decisión con respecto al desarrollo formal de sus obras es lo que le da a Samanta la posibilidad de hacer que sus fabulaciones puedan ser asumidas como reales por parte del espectador, dado que las técnicas que utiliza se encuentran en un estado intermedio entre el realismo y la fabulación. Esto es similar a la propuesta del docente Asier Mensuro para el stop motion, cuando señala que esta técnica "parece colocarse a medio camino entre la realidad cinematográfica y la creación autónoma de los dibujos animados y, posiblemente, en esa hibridación resida su encanto especial" (Mensuro, 2010, p. 69). En palabras de la artista:

Las animaciones hacen creíble lo que llamaríamos absurdo, ya que las historias aquí narradas no son dibujos ni caricaturas, sino personajes reales interpretados por actores que interactúan con los objetos vivos dentro de una casa, esto nos debe hacer pensar que podemos crear y creer más allá de lo que vemos y conocemos. Que realmente es posible que un sillón camine o que una escalera estornude. (Duque, 2011, p. 23)

De la misma manera en que Duque es consciente del porqué de la elección del medio y la técnica que emplea, también tiene claro el proceso que debe llevar a cabo para obtener los resultados deseados con su trabajo. En sus memorias de grado titulada Confusiones y otras realidades (2011), explica las etapas para la realización de sus obras: primero, se inspira en sus propios sueños, que luego transforma en guiones, para posteriormente fotografiar las escenas y finalmente hacer la posproducción de forma digital. Pero el proceso de sus animaciones no termina allí, pues para ella es sumamente importante la etapa de divulgación y exhibición. Samanta no se limita a mostrar sus animaciones proyectadas 
o en una sola pantalla, sino que crea juegos narrativos con el uso de varios canales; en este caso, distintos televisores, donde sus personajes pasan de un espacio a otro, rompiendo los límites de la pantalla y encontrando realidades regidas por reglas diferentes a las habituales. Ese es el caso de obras como Un final (2010), Dos puntos (2010) y Tres puntos (2010), donde la animación deja de ser completamente bidimensional, para comenzar a expandirse en el espacio de exposición a través de un personaje que se pasea entre las distintas pantallas, generando así diálogos y rupturas del espacio y el tiempo audiovisual, e interesantes dinámicas con el espectador. Al respecto la artista señala: "Son propuestas que surgieron queriendo que el video interactuara con el espacio y que el espectador sintiera aún más desconcierto con las imágenes rompiendo la realidad nuestra con la del personaje" (Duque, 2011, p. 32).
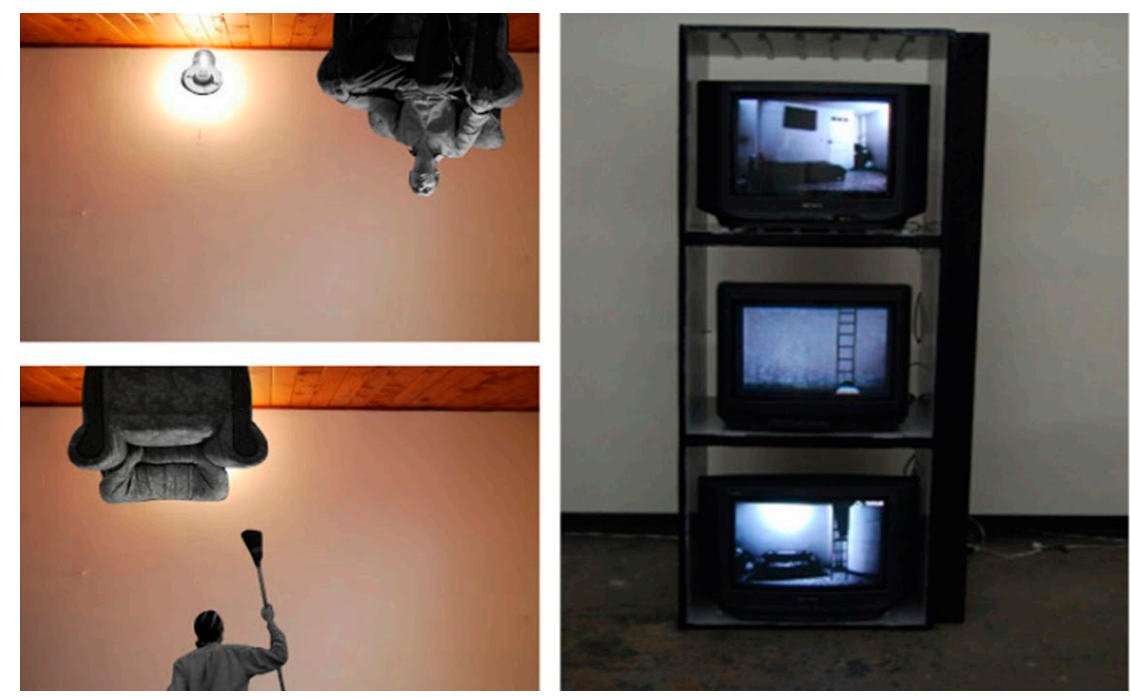

Figura 6. Tres puntos. Videoinstalación. A la derecha, fotogramas de la animación; a la izquierda, registro de la videoinstalación en la sala de exposiciones.
Fuente: Duque (2010). 
Estas animaciones asombran por su juego con la noción que tenemos de realidad: objetos cotidianos que cobran vida, personajes que se ven sorprendidos por cambios repentinos en su entorno y televisores a través de los que se diluyen los límites de la pantalla y lo real. Todo ello posible, como Samanta Duque lo menciona, gracias a la versatilidad y características estéticas propias de la animación. En las obras de esta artista se puede intuir un conocimiento técnico y un interés creciente por explotar las posibilidades expresivas de la animación, con la que consigue expresar artísticamente sus inquietudes y cuestionar al espectador, al hacer que la imaginación, los sueños y el absurdo se transformen en realidad.

\section{Resultados y hallazgos}

La investigación realizada condujo al planteamiento de un primer documento sobre el estado del arte de propuestas con animación en procesos de formación artística en la Facultad de Artes de la UdeA, estructurada desde tres categorías de análisis de convergencia y relacionamiento de medios expresivos. Dado que la época estudiada fue la del tránsito entre los medios análogos de producción hacia los digitales, la forma utilizada en el análisis permitió encontrar una suerte de sincretismo de medios que no solo equilibra las posibilidades sobre perspectivas homogeneizantes que puedan atribuirse a las producciones artísticas desde el concepto de convergencia, para favorecer un estudio que permite entender estas obras desde su materialidad expresiva, generando así posibilidades de relacionamiento o, más bien, posicionamiento historiográfico y estético. Esta idea se alimenta de la consideración que Steve F. Anderson, en su artículo Aporias of the Digital Avant-Garde, señala sobre el concepto de medios sincréticos:

Syncretic media, by definition, retain traces of the various competing and sometimes contradictory forms of which they are composed. In the process, these hybrid works announce a relationship to their medium that invites us to ask the right questions about how they are constructed and the 
potential relevance of medium specificity to understanding their importance. Arguably, it is through the foregrounding rather that the effacement of the material substrates underlying certain instances of digital media, that we find the most suggestive and historiographically relevant traces. (Anderson, 2006, p. 10)

De otro lado, en el proceso de revisión de las memorias de grado y catálogos de exposiciones se encontró que dicho material es un aporte documental de gran valor para la construcción y difusión científica en el campo de la imagen animada realizada por los estudiantes de la facultad. En particular, la cantidad de las memorias de grado de sus egresados, así como los catálogos de eventos locales, permitieron proponer el estado del arte del cual deriva el presente artículo. Sin embargo, aún se observa la necesidad de determinar categorías de sistematización más cercanas a las realidades artísticas de los procesos documentados sobre las obras y las metodologías conducentes a su creación, y, en especial, sobre aquellos documentos que incluyen animación en las artes.

En general, se observa que, debido al perfil de los programas académicos estudiados, las producciones que integran animación en las artes plásticas y visuales, pocas veces nombran la animación explícitamente de modo que los productos u obras son denominados y definidos en relación a la convergencia de medios o a su semejanza con medios considerados preponderantes o que se encuentran relacionados al interés semántico de cada propuesta.

Dado que en la facultad, para el periodo analizado no se contaba con procesos de enseñanza específicos en producción y experimentación animada, los desarrollos que se generaron partieron de una libertad formativa y expresiva de docentes y estudiantes, la cual facilitó el distanciamiento de los cánones tradicionales para la animación. También es posible decir que los procesos pedagógicos sobre la producción animada respondieron más a una demanda técnica o expresiva en diálogo con otro medio, mas no a las preguntas que 
podrían surgir desde el interés de formarse como artista de la animación y de desarrollar animaciones de autor.

Finalmente, es posible señalar que, para el caso de las artes, se pueden dar formas de enseñanza y de expresión artística con animación fuera de estándares metodológicos de la producción comercial, centrándose en el trabajo empírico desde el fortalecimiento del pensamiento creativo, libre de condicionamientos técnicos. Lo anterior, gracias a que el desarrollo de determinados procesos para la creación de imágenes en movimiento es motivado por la formulación de preguntas abiertas en las que se plantean posibles relaciones que, durante la experimentación, suceden entre los medios y los temas o intenciones propuestos por los artistas en formación.

\section{Conclusiones}

El análisis realizado en el presente texto permite evidenciar las formas en que la animación ha sido integrada a los procesos artísticos desarrollados por los estudiantes de los programas de Artes Plásticas y de Licenciatura en Educación Artes Plásticas, de la Universidad de Antioquia, durante la primera década de siglo xxi. Se observa que esta integración se dio a través de procesos experimentales en los que primaba el interés por el medio, la posibilidad de dar vida a la imagen, y la búsqueda por construir narrativas y poéticas a través del diálogo entre la animación y otros medios. Aunque para el proceso de creación con animación no se contaba con equipos especializados, la experimentación con este medio se integró en diversos procesos de formación, como el curso de video dictado por el profesor Saúl Montoya, el curso de animación del profesor Luis Ángel Castro y los talleres complementarios en imagen digital; y en la estructura metodológica de los talleres de integrado y de grado. Lo anterior generó un crecimiento continuo del uso y reflexión de la animación como medio de creación en sí misma y como soporte que se integra a otras formas 
de expresión artística. También, por el análisis realizado se observa que hay tres categorías por las cuales consideramos que se integró la animación a los procesos de experimentación artística: convergencia de medios por necesidad expresiva, recursividad para trabajar la imagen en movimiento, e interés en el medio como lenguaje de expresión. Se observa también que, dadas las preocupaciones artísticas y conceptuales de los estudiantes, los usos de la animación fueron bastante amplios, Ilevando a que muchas veces las obras no fueran catalogadas como animaciones sino bajo otras denominaciones.

Asimismo, se concluye que las asignaturas que comenzaron a dictarse en el 2000 con programas como Macromedia Flash, con el profesor Luis Castro (y en combinación con las áreas de gráfica, escultura y video), facilitaron la experimentación, dando como resultado un potencial expresivo y comunicativo, antes que la impecabilidad técnica de las propuestas realizadas en los procesos de investigación-creación de los talleres de integrado y de grado. Dada la experimentación formal, es de resaltar que en muchas propuestas la animación entra en juego con objetos, espacios, cuerpos (espectadores y artistas) y pantallas no convencionales; haciendo que se pueda pensar en una animación expandida, más allá de los límites espaciales de la pantalla y de los lineamientos convencionales de la producción audiovisual.

\section{Referencias}

Alonso, M. y Mantilla, L. (2001). Imágenes en acción: análisis y práctica de la expresión audiovisual en la escuela activa. Madrid: Akal.

Anderson, S. (2006). Aporias of the Digital Avant-Garde. En: Intelligent agent. 06.02, pp. 1-12. ISEA 2006 issue. ApoLichty, P (Editor-in-Chief) \& Paul, C (Director) (2006). New York: Intelligent Agent Inc. 
Bedoya, J. [Julián Bedöx], (2008). «Un barquito, 1 (estudios de stop motion)». Serie El barquito. Archivo de video. Recuperado de https://www.youtube. $\mathrm{com} /$ watch? reload $=9 \& \mathrm{v}=\mathrm{R}-\mathrm{B} 3 \mathrm{NavGpEU}$

Bedoya, J. [Julián Bedöx], (2008). «Un barquito, 2» (estudios de stop motion). Serie El barquito. Archivo de video. Publicado el 21 de octubre del 2010 en: https://www.youtube.com/watch?v=OC3kqNPZYd4

Bedoya, J. [Julián Bedöx], (2008). «Un barquito, 3» (estudios de animación y stop motion). Serie El barquito. Archivo de video. Publicado el 28 de octubre del 2010 en: https://www.youtube.com/watch?v=OYKpN0b5Gik

Bedoya, J. [Julián Bedöx], (2008). «Un barquito, 4» (estudios de stop motion). Serie El barquito. Archivo de video. Publicado el 4 de noviembre del 2010 en: https://www.youtube.com/watch?v=hJflBfZOvpg

Arce, R., Sánchez, C., y Velázquez, O. (2013). La animación en Colombia hasta finales de los años 80. Bogotá: Universidad Jorge Tadeo Lozano.

Bordwell, D. (1996). La narración en el cine de ficción. Barcelona: Paidós.

Duque, S. (2011). Confusiones y otras realidades (Memorias de grado para optar al título de Maestra en Artes Plásticas). Universidad de Antioquia, Medellín.

Jenkins, H. (2006). Convergence culture: la cultura de la convergencia de los medios de comunicación. Barcelona: Paidós.

Mensuro, A. (2010). Cine de muñecos. Stop motion animation. En Ramos, M. y Ruiz, A. (Eds.), Estéticas de la animación. Madrid: MAIA, pp. 65-83.

Montoya, S. (2001). La producción de videos: procesos y modos de expresión. Medellín: Universidad de Antioquia. 
Munárriz, J. (2012). Animación: imagen en movimiento en la creación artística (se mueve). Recuperado de https://www.academia.edu/2242406/ ANIMACI\%C3\%93N_Imagen_en_movimiento_en_la_creaci\%C3\%B3n_ art\%C3\%ADstica_Se_Mueve_

Orós C. y José L. (2010). Adobe Flash CS4 professional. Curso práctico. México: Alfaomega/Ra-Ma.

Pascual, F. (2016). Guía de campo de Adobe Photoshop CS y 7. Madrid: Ra-Ma.

Paul, C. (2003). Digital art. New York: Thames \& Hudson.

Pikkov, Ü. (2010). Animasophy: theoretical writings on the animated film. Tallin: Estonian Academy of Arts.

Quiceno, Y. y Grajales, A. (2012). La casa, la familia y los recuerdos de infancia. Expresión artística a partir de la memoria autobiográfica (Monografía para optar al título de Licenciatura en Educación Artes Plásticas). Universidad de Antioquia, Medellín.

Ratner, P. (2005). Animación 3D. Barcelona: Anaya.

Restrepo, J. (2005). Summa Technologiae: La obra de arte en la época de la reproductibilidad electrónica. En Hernández, I. (Ed.), Estética, ciencia y tecnología: creaciones electrónicas y numéricas. Bogotá: Pontificia Universidad Javeriana, pp. 225-33.

Como citar: Restrepo, I. C, Tabares, A. M., Sánchez, C. M. y Roldán, S. (2020). Más allá de la pantalla: tres casos sobre la animación en los procesos académicos y de expresión artística de la Facultad de Artes de la Universidad de Antioquia (2000-2010). Revista KEPES, 17(22), 367-396.

https://doi.org/10.17151/kepes.2020.17.22.14 